\title{
Intra-articular magnesium to alleviate postoperative pain after arthroscopic knee surgery: a meta-analysis of randomized controlled trials
}

\author{
Lijun Shi $^{1+}$, Haiyun Zhu ${ }^{2+}$, Jinhui Ma ${ }^{3+}$, Li-Li Shi ${ }^{4}$, Fuqiang Gao ${ }^{3}$ and Wei Sun ${ }^{1,3^{*}}$
}

\begin{abstract}
Objective: We aimed to evaluate the safety and efficacy of intra-articular (IA) magnesium (Mg) for postoperative pain relief after arthroscopic knee surgery.

Methods: We searched PubMed, Embase, Medline, Cochrane library, and Web of Science to identify randomized controlled trials that compared postoperative pain outcomes with or without IA Mg after knee arthroscopy. The primary outcomes were pain intensity at rest and with movement at different postoperative time points and cumulative opioid consumption within $24 \mathrm{~h}$ after surgery. Secondary outcomes included the time to first analgesic request and side effects.

Results: In total, 11 studies involving 677 participants met the eligibility criteria. Pain scores at rest and with movement 2 , 4,12 , and $24 \mathrm{~h}$ after surgery were significantly lower, doses of supplementary opioid consumption were smaller, and the time to first analgesic requirement was longer in the IA Mg group compared with the control group. No significant difference was detected regarding adverse reactions between the groups.

Conclusions: Intra-articular magnesium is an effective and safe coadjuvant treatment for relieving postoperative pain intensity after arthroscopic knee surgery.

Protocol registration at PROSPERO: CRD42020156403.
\end{abstract}

Keywords: Intra-articular, Magnesium, Arthroscopic knee surgery, Postoperative pain, meta-analysis

\section{Introduction}

Arthroscopic knee surgery is an established orthopedic procedure that is performed for diagnostic and therapeutic purposes for intra-articular lesions. It has replaced classic arthrotomy in many cases due to its smaller surgical incision, fewer complications, and faster

\footnotetext{
* Correspondence: sun887@163.com

${ }^{\dagger}$ Lijun Shi, Haiyun Zhu and Jinhui Ma contributed equally to this work. 'Department of Orthopedic, Surgery Graduate School of Peking Union Medical College, China-Japan Friendship institute of Clinical Medicine, 2 Yinghuadong Road, Chaoyang District, 100029 Beijing, China

${ }^{3}$ Department of Orthopaedic Surgery, China-Japan Friendship Hospital, 2 Yinghuadong Road, Chaoyang District, Beijing 100029, China

Full list of author information is available at the end of the article
}

recovery $[1,2]$. However, this procedure is sometimes associated with moderate to acute postoperative pain, which may hinder early mobilization and rehabilitation, and prolong hospital stays; all of which affect patient satisfaction. Therefore, it is essential to strengthen postoperative pain management and enhance convalescence after surgery.

Currently, various strategies have been introduced for the early postoperative pain management after arthroscopic knee surgery, including oral opioid analgesics, intravenous patient-controlled analgesia, and peripheral nerve blocks [3]. Neuraxial blocks such as spinal or epidural analgesia are no longer the first choice for fast-

(c) The Author(s). 2021 Open Access This article is licensed under a Creative Commons Attribution 4.0 International License, which permits use, sharing, adaptation, distribution and reproduction in any medium or format, as long as you give appropriate credit to the original author(s) and the source, provide a link to the Creative Commons licence, and indicate if changes were made. The images or other third party material in this article are included in the article's Creative Commons licence, unless indicated otherwise in a credit line to the material. If material is not included in the article's Creative Commons licence and your intended use is not permitted by statutory regulation or exceeds the permitted use, you will need to obtain permission directly from the copyright holder. To view a copy of this licence, visit http://creativecommons.org/licenses/by/4.0/ The Creative Commons Public Domain Dedication waiver (http://creativecommons.org/publicdomain/zero/1.0/) applies to the data made available in this article, unless otherwise stated in a credit line to the data. 
track arthroscopic surgery because of their various side effects, including headache, epidural hematoma, urinary retention, and prolonged motor block. Recent studies have recommended intraarticular (IA) drug administration for pain control due to their ability to directly block nociceptive stimuli at the local site, with less systemic absorption [4,5]. Commonly used IA drugs in clinical practice include opioids (morphine, pethidine, fentanyl, and sufentanil), corticosteroids, clonidine, ketorolac, and local anesthetics (bupivacaine, levobupivacaine, lignocaine, lignocaine, and ketamine) [6-10]. A relatively new approach is the use of IA magnesium $(\mathrm{Mg})$, which recently has been studied extensively.

$\mathrm{Mg}$ plays an important role in maintaining organismal homeostasis, and it is also a crucial element for cellular signal transduction [11]. Animal studies have demonstrated that $\mathrm{Mg}$ can alter the duration and perception of pain as it antagonizes $\mathrm{N}$-methyl-D-aspartate (NMDA) receptors [12]. NMDA receptors not only participate in central sensitization, modulation, and nociceptive transmission of acute pain [13] but also correlate with the peripheral sensory transmission of noxious signals. In addition to their central location, NMDA receptors are also located within the peripheral skin [14], muscles [15], and the knee joint [16], where they contribute to human pain after activation [15]. At resting states without stimulus, NMDA receptors are blocked by the presence of $\mathrm{Mg}$ ions. Upon receiving afferent activities, nociceptor fibers dislodge $\mathrm{Mg}$ ions from the NMDA receptor, activating nociceptors to produce pain.

Clinically, the identified routes of $\mathrm{Mg}$ administration for postoperative pain control include intrathecal, epidural, systemic, and topical use, which result in different effects [17-19]. Among these routes, the IA route is likely to be more acceptable for patients due to its intrinsic safety and minimal side effects. Although a large number of clinical studies have been performed to determine the effects of IA Mg administration on postoperative pain outcomes, the findings remain controversial [20-22].

Therefore, the major objective of this quantitative meta-analysis of randomized controlled trials (RCTs) was to investigate the effect of IA $\mathrm{Mg}$ on acute pain management outcomes after arthroscopic knee surgery. A secondary aim was to evaluate possible side effects related to the administration of IA Mg.

\section{Methods}

We performed this meta-analysis in accordance with the guidelines of the Preferred Reporting Items for Systematic Reviews and Meta-Analysis (PRISMA) [23].

\section{Literature search}

Three authors (Lijun Shi, Haiyun Zhu, and Jinhui $\mathrm{Ma}$ ) independently searched (first by title and abstract, and then by full text) the electronic databases PubMed, Medline, Embase, Web of Science, and Cochrane library from inception until October 30, 2020. The words and MESH terms "Intra-Articular," "Magnesium," "Arthroscopy," "Postoperative," and "Pain" were searched individually and in different combinations. A manual search of references from eligible and relevant studies was performed to find additional trials. No restrictions were imposed regarding language or publication status.

\section{Inclusion and exclusion criteria}

Eligible studies were required to meet the following inclusion criteria: (1) RCTs, (2) participants undergoing arthroscopic knee surgery, (3) administration of $\mathrm{Mg}$ through the IA route, (4) including an experimental group of IA $\mathrm{Mg}$ or IA $\mathrm{Mg}$ plus a local anesthetic, and (5) including a control group of saline or local anesthetic alone. The exclusion criteria were as follows: (1) nonRCTs; (2) reviews, letters, abstracts, case series, or editorials; (3) the administration of $\mathrm{Mg}$ not through the IA route; and (4) studies with insufficient data.

\section{Study selection}

Two authors (Lijun Shi and Lili Shi) independently assessed the initial search results to exclude irrelevant trials and identify eligible studies according to the inclusion and exclusion criteria by screening titles and abstracts. Full texts of any potentially useful studies were reviewed. Any discrepancies were resolved by consulting with a third author (Wei Sun or Fuqiang Gao).

\section{Data abstraction}

Two authors (Lijun Shi and Haiyun Zhu) independently evaluated the included studies and extracted trial details using special data collection forms developed for this investigation. Disagreements were resolved by consensus or consultation with a third author (Wei Sun or Fuqiang Gao).

We first extracted data from tables or text. For data not reported numerically, we extracted them from available figures using the software GetData (http://getdatagraph-digitizer.com/index.php). Continuous data were reported using means and standard deviations (SD), and data presented in terms of the median and range were converted to means and SD [24]. For trials that involved more than one experimental group in comparison with a single control group, the relevant comparisons to the comparator were split for primary analysis.

The data extracted from trials included the first author, year of publication, sample size, patient baseline 
characteristics, type of surgery, type of anesthesia, IA $\mathrm{Mg}$ dose, pain scores at rest and with movement (postoperative 2, 4, 12 and 24 h), cumulative opioid consumption, time to first rescue analgesic request (min), and adverse events. The pain intensity was measured using the 10-point visual analog scale (VAS), where 0 means no pain and 10 means the most severe pain. The numerical rating scale (NRS) of pain was converted to a VAS score. Postoperative opioid consumption within 24 $\mathrm{h}$ was converted to the equivalent dosage of intravenous (IV) morphine [25].

The primary outcomes of interest were the pain VAS scores at rest and with movement at different postoperative time points and total opioid consumption (IV morphine equivalent, $\mathrm{mg}$ ) in the first 24-h postoperative period. The secondary outcomes included the time to first analgesic requirement (min) and the incidence of side effects.

\section{Assessments of the risk of bias and methodological quality}

Two senior authors (Fuqiang Gao and Wei Sun) independently evaluated the methodological quality of the included studies using the Cochrane Collaboration's Risk of bias tool [26], which contains seven domains: random sequence generation, allocation concealment, blinding of participants and personnel, blinding of outcome assessment, incomplete outcome data, selective outcome reporting, and other sources of bias. The risk of bias was defined as high, low, and unclear. Disagreements were resolved by discussion.

The quality of evidence for each outcome was judged with the Grading of Recommendations Assessment, Development and Evaluation (GRADE) methodology [27], which consists of five items: study limitations, inconsistency of results, indirectness of evidence, imprecision, and reporting bias. This methodology categorizes the

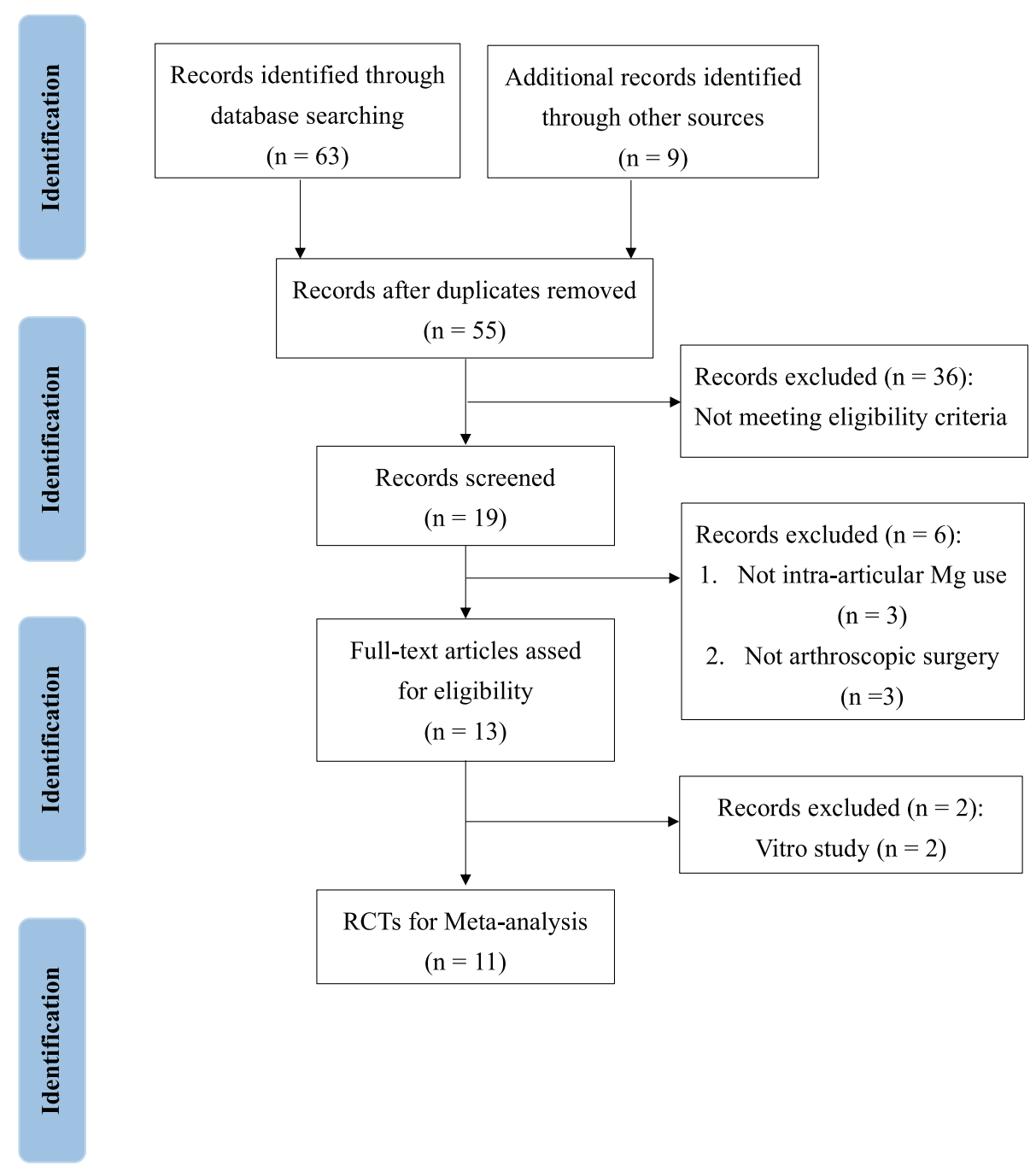

Fig. 1 Flow chart of the randomized controlled trials selection process 


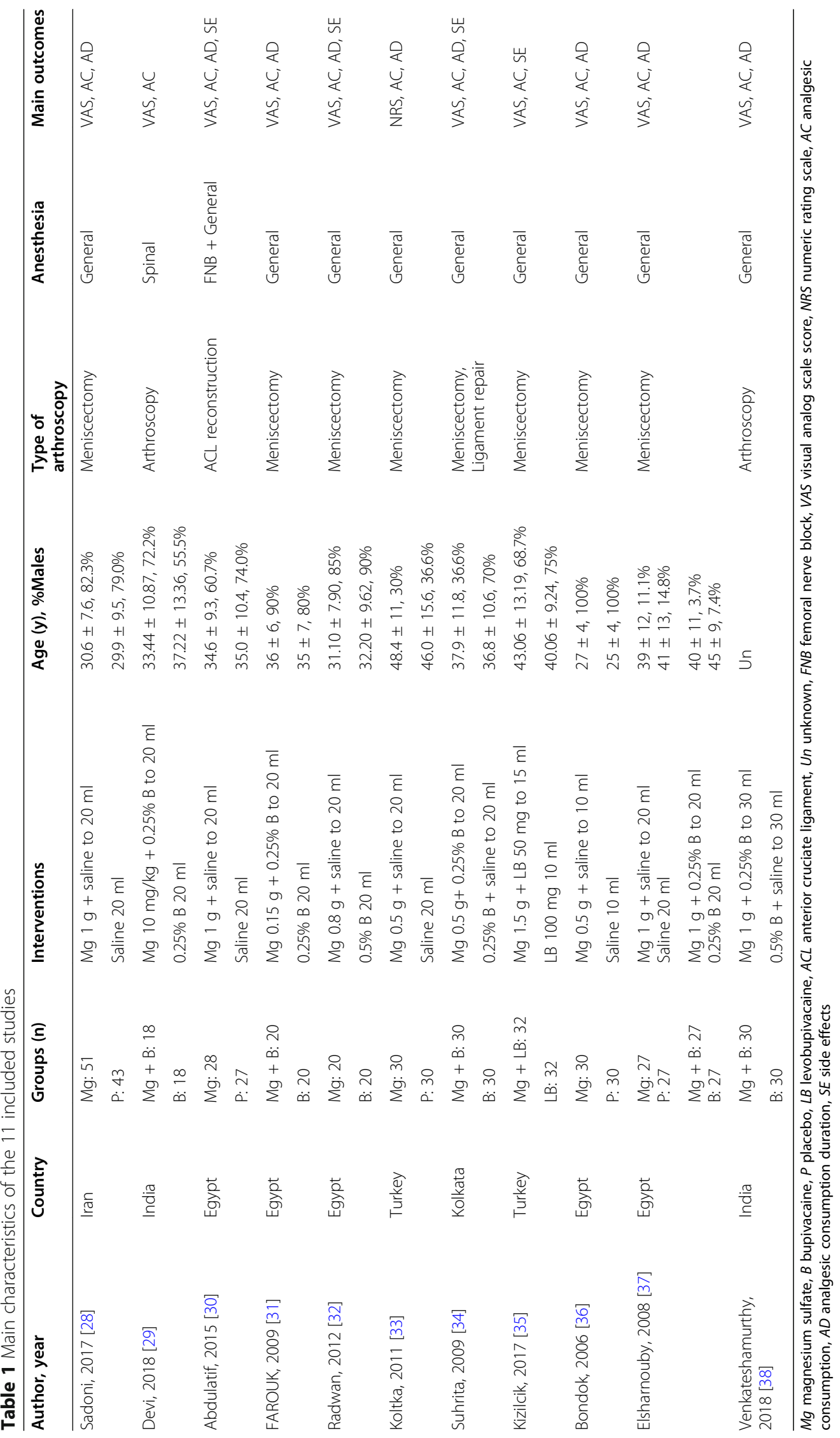


strength of evidence as high, moderate, low, or very low, and each of these items may be used to define the quality level. This process was conducted using Grade Profiler software (GRADEpro version 3.6).

\section{Statistical analysis}

All statistical analyses were conducted using Review Manager software (RevMan version 5.3). Continuous variables are reported as mean differences (MD) with 95\% confidence intervals (CIs). As the incidence of adverse events was very low, only qualitative analysis and description was performed. Statistical heterogeneity was measured and reported as $I^{2}$, which describes the percentage of the total variability caused by heterogeneity rather than by chance. The $I^{2}$ values ranged between 0 and $100 \%$, where values above 50 and $75 \%$ represent substantial and considerable heterogeneity, respectively. If the heterogeneity was significant $\left(p<0.05, I^{2}>50 \%\right)$, the random-effects model was used. Otherwise, the fixed-effects model was adopted $\left(p>0.05, I^{2}<50 \%\right)$. Sensitivity analysis was further performed by removing one trial at a time to explore possible explanations for heterogeneity and to identify the influence of a single $\mathrm{RCT}$ on the overall mean differences.

\section{Results}

Search results and selected articles

Figure 1 illustrates the screening process of literature search. Finally, from the retrieved studies, 11 (published between 2006 and 2018) [28-38] met the inclusion criteria and were qualified for this metaanalysis. The main characteristics of the included studies (including 677 participants) are summarized in Table 1. Five studies compared IA $\mathrm{Mg}$ versus saline or bupivacaine alone $[28,30,32,33,36]$, five other studies compared IA $\mathrm{Mg}$ plus bupivacaine versus bupivacaine $[29,31,34,35,38]$, while one study contained these two kinds of comparisons [37], and both were included. All studies were of RCT design with individual sample sizes ranging from 18 to 51 .

\section{Study quality and GRADE of evidence}

Figure 2 is a summary of the risk of bias assessment. Two studies [30,31] did not describe their random sequence generation (high risk of selection bias) and four $[28,31,34,35]$ did not design a clear allocation concealment plan (unclear or high risk of selection bias). All trials adopted the double-blind method, except one [33], which adopted a single-blind method (high risk of
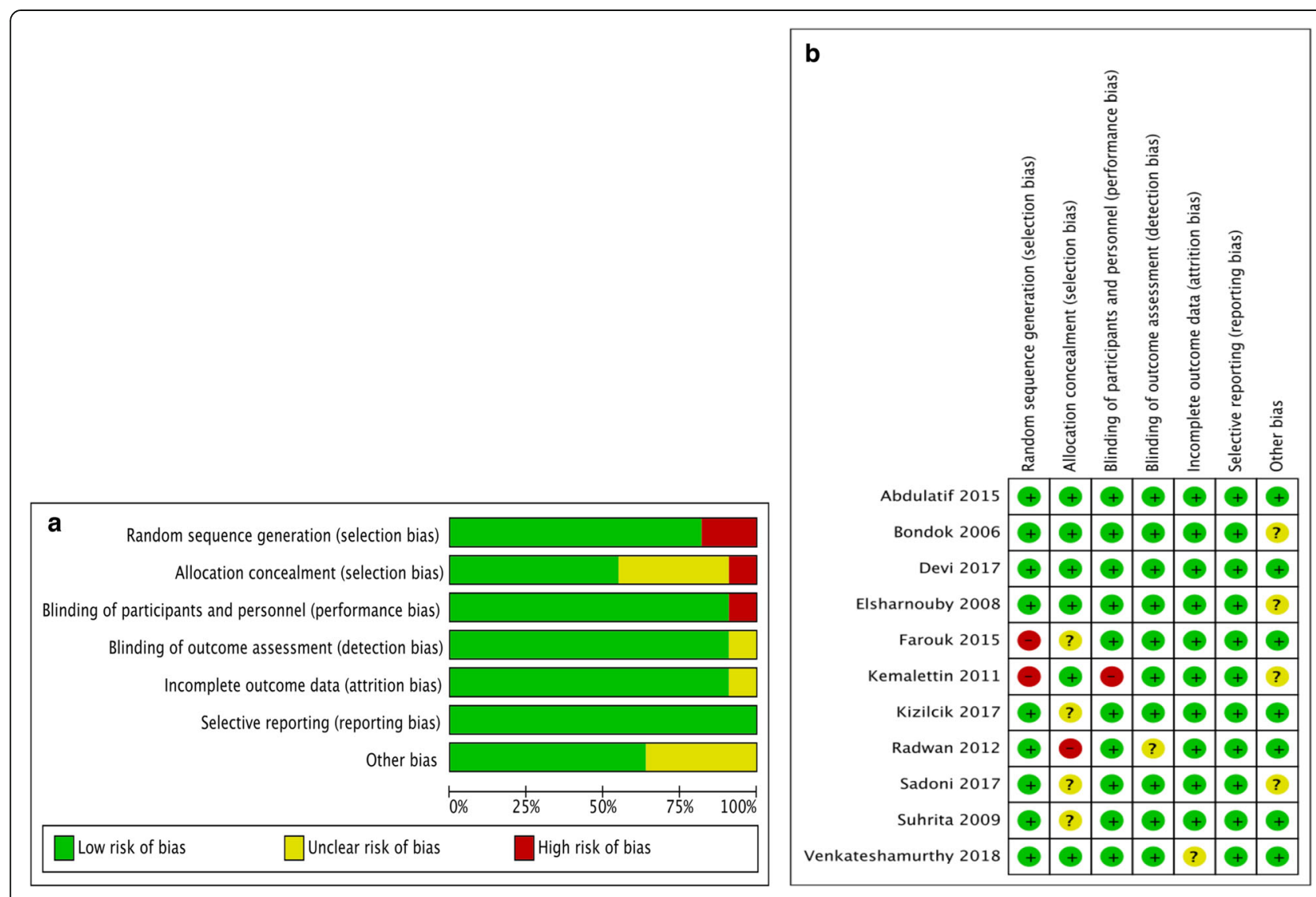

Fig. 2 Risk of bias assessment for the included randomized controlled trials 
performance bias). The GRADE level of evidence for each RCT is shown in Table 2, and the quality was mostly high or moderate.

\section{Meta-analysis results \\ VAS scores at rest}

The pooled effects of IA $\mathrm{Mg}$ on postoperative pain after arthroscopic knee surgery are summarized in Table 2. Nine studies, including ten trials, compared the pain intensity at rest between IA Mg participants and non-IA Mg participants. As shown in Fig. 3, IA $\mathrm{Mg}$ was associated with significantly lower VAS scores at postoperative $2 \mathrm{~h}(\mathrm{MD}=-0.74,95 \% \mathrm{CI}$ : 0.84 to $\left.-0.64 ; p=0.51 ; I^{2}=0 \%\right), 4 \mathrm{~h}(\mathrm{MD}=-0.24$, 95\% CI: -0.37 to $\left.-0.11 ; p=0.11 ; I^{2}=45 \%\right), 12 \mathrm{~h}$ $\left(\mathrm{MD}=-0.53,95 \% \mathrm{CI}:-0.64\right.$ to $-0.41 ; p=0.10 ; I^{2}$ $=47 \%)$, and $24 \mathrm{~h}(\mathrm{MD}=-0.33,95 \% \mathrm{CI}:-0.42$ to $0.24 ; p=0.20 ; I^{2}=30 \%$ ) (Table 2). The heterogeneity was all acceptable; hence, a fixed-effects model was used, and further sensitivity analysis was not performed.

\section{VAS scores with movement}

Seven trials compared the postoperative pain intensity with movement between two groups. As shown in Fig. 4, IA $\mathrm{Mg}$ was associated with significantly lower VAS scores at postoperative $2 \mathrm{~h}(\mathrm{MD}=-0.46,95 \% \mathrm{CI}:-0.64$ to $\left.0.27 ; p=0.14 ; I^{2}=39 \%\right), 4 \mathrm{~h}(\mathrm{MD}=-0.85,95 \% \mathrm{CI}:-1.40$ to $\left.-0.30 ; p<0.0001 ; I^{2}=95 \%\right), 12 \mathrm{~h}(\mathrm{MD}=-0.83,95 \%$ CI: -1.17 to $\left.-0.48 ; p=0.004 ; I^{2}=71 \%\right)$, and $24 \mathrm{~h}(\mathrm{MD}=$ $-0.58,95 \%$ CI: -0.79 to $-0.36 ; p=0.05 ; I^{2}=45 \%$ ) (Table 2 ). But the heterogeneity was significant at postoperative $4 \mathrm{~h}$, sensitivity analysis demonstrated that removal of the study by Kemalettin et al. [33] significantly changed the results (MD $=-0.51,95 \% \mathrm{CI}:-0.62$ to $-0.39 ; p=0.45 ; I^{2}$ $=0 \%$ ). In this RCT, postoperative analgesia was maintained by IV tramadol during the first $4 \mathrm{~h}$ after surgery. Meanwhile, sensitivity analyses after excluding one trial at a time still showed a substantial heterogeneity in the pain outcomes at postoperative $12 \mathrm{~h}$.

\section{Postoperative opioid consumption}

Eight trials compared the postoperative opioid consumption (IV morphine equivalent) between two groups. As shown in Fig. 5, IA Mg was associated with significantly less opioid consumption within postoperative $24 \mathrm{~h}$ (MD $=-4.23,95 \%$ CI: -4.64 to $\left.-3.82 ; p=0.21 ; I^{2}=27 \%\right)$ (Table 2). No statistical heterogeneity was observed, and a fixed-effects model was used.

\section{Time to first analgesic request ( $\mathrm{min}$ )}

Eleven trials compared the time to first analgesic request after surgery between two groups. As shown in Fig. 6, IA $\mathrm{Mg}$ was associated with significantly prolonging of the time to analgesic requirement $(\mathrm{MD}=329.99,95 \% \mathrm{CI}$ : 228.73-431.24; $p<0.00001 ; I^{2}=99 \%$ ) (Table 2). The

Table 2 The GRADE evidence quality for each outcome

\begin{tabular}{|c|c|c|c|c|c|}
\hline Outcome & $\begin{array}{l}\text { Number of } \\
\text { Included Studies }\end{array}$ & $\begin{array}{l}\text { Total Participants } \\
\text { (Mg/ Control) }\end{array}$ & MD $(95 \% \mathrm{Cl})$ & Heterogeneity & $\begin{array}{l}\text { Quality of Evidence } \\
\text { (GRADE) }\end{array}$ \\
\hline \multicolumn{6}{|l|}{ VAS at rest } \\
\hline at $2 \mathrm{~h}$ & 8 & $212 / 211$ & $-0.74(-0.84,-0.64)$ & $P^{2}=0 \%, P=0.51$ & LOW \\
\hline at $4 \mathrm{~h}$ & 6 & 152/151 & $-0.24(-0.37,-0.11)$ & $\mathrm{I}^{2}=45 \%, P=0.11$ & MODERATE ${ }^{d}$ \\
\hline at $12 \mathrm{~h}$ & 6 & $152 / 152$ & $-0.53(-0.64,-0.41)$ & $I^{2}=47 \%, P=0.10$ & $\mathrm{HIGH}$ \\
\hline at $24 \mathrm{~h}$ & 7 & $186 / 186$ & $-0.33(-0.42,-0.24)$ & $I^{2}=30 \%, P=0.20$ & $\mathrm{HIGH}$ \\
\hline \multicolumn{6}{|l|}{ VAS with movement } \\
\hline at $2 \mathrm{~h}$ & 7 & $140 / 139$ & $-0.46(-0.64,-0.27)$ & $\mathrm{I}^{2}=39 \%, P=0.14$ & $\mathrm{HIGH}$ \\
\hline at $4 \mathrm{~h}$ & 6 & $150 / 149$ & $-0.85(-1.40,-0.30)$ & $P^{2}=95 \%, P<0.00001$ & MODERATE $^{b}$ \\
\hline at $12 \mathrm{~h}$ & 6 & $150 / 149$ & $-0.83(-1.17,-0.48)$ & $\mathrm{I}^{2}=71 \%, P=0.004$ & MODERATE $^{c}$ \\
\hline at $24 \mathrm{~h}$ & 7 & 170/169 & $-0.58(-0.79,-0.36)$ & $I^{2}=45 \%, P=0.09$ & $\mathrm{HIGH}$ \\
\hline Anesthetic Consumption & 8 & $229 / 220$ & $-4.23(-4.64,-3.82)$ & $I^{2}=27 \%, P=0.21$ & $\mathrm{HIGH}$ \\
\hline Anesthetic duration & 11 & $311 / 302$ & $329.99(228.73,431.24)$ & $P^{2}=99 \%, P<0.00001$ & $\mathrm{LOW}^{\mathrm{b}}$ \\
\hline
\end{tabular}

(1) GRADE working group grades of evidence:

High quality: Further research is very unlikely to change our confidence in the estimate of effect

Moderate quality: Further research is likely to have an important impact on our confidence in the estimate of effect and may change the estimate

Low quality: Further research is very likely to have an important impact on our confidence in the estimate of effect and is likely to change the estimate

Very low quality: Any estimate of effect is very uncertain

(2) Explanations:

${ }^{\text {a }}$ Study limitation: included trials are quasi design

bInconsistency of results: large heterogeneity

Indirectness of evidence: large differences between the interventions in different trials

dimprecision: small sample size and wide $95 \% \mathrm{Cl}$

${ }^{\mathrm{e}}$ Reporting bias: positive values showing benefits of the studied intervention 


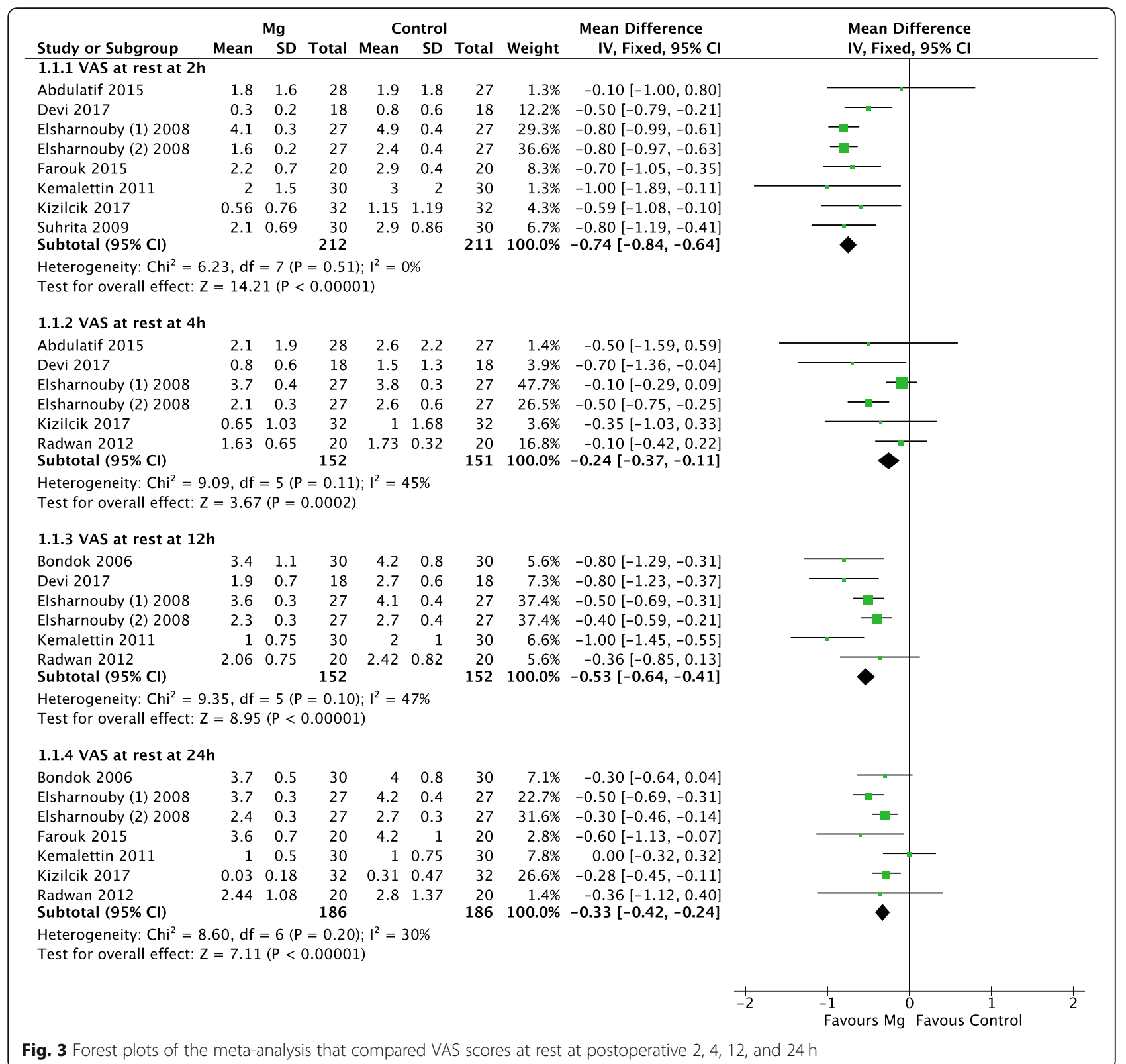

heterogeneity was considerable; however, further sensitivity analysis did not change the heterogeneity when any of the studies were removed.

\section{Safety analysis}

Only three included RCTs reported adverse reactions. In the study by Abdulatif et al. [30], postoperative shivering was observed in 12 and 10 patients in the IA Mg administration $(n=28)$ and control $(n=27)$ groups, respectively. In the RCT conducted by Radwan et al. [32], one patient in both the IA $\mathrm{Mg}(n=20)$ and placebo $(n=20)$ groups developed knee effusion. In the study conducted by Suhrita et al. [34], two patients developed hypotension and bradycardia in the IA $\mathrm{Mg}$ group $(n=$
$30)$, while no side effects were observed in the placebo group $(n=30)$. There was no statistically significant difference between the comparable groups in each RCT.

\section{Discussion}

The chief finding of this study was that IA Mg can significantly relieve pain intensity within the 24-h postoperative timeframe after arthroscopic knee surgery. The VAS scores at rest or with movement were lower in the IA $\mathrm{Mg}$ group than in the non-IA Mg group. Furthermore, the IA Mg group showed lower postoperative opioid consumption and the time to first analgesic request after surgery was longer, which would help reduce the risk of opioid-related complications. Though three 


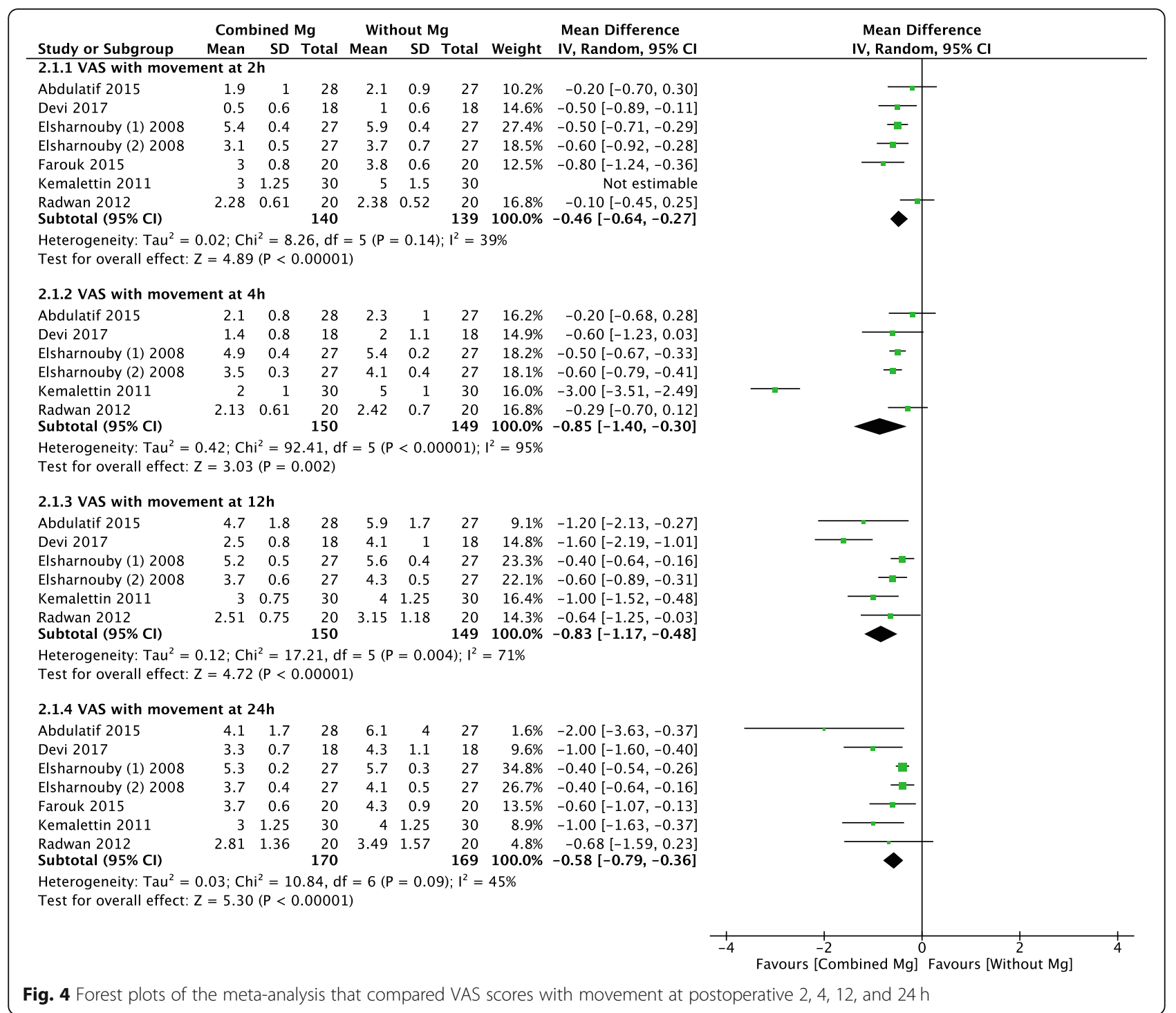

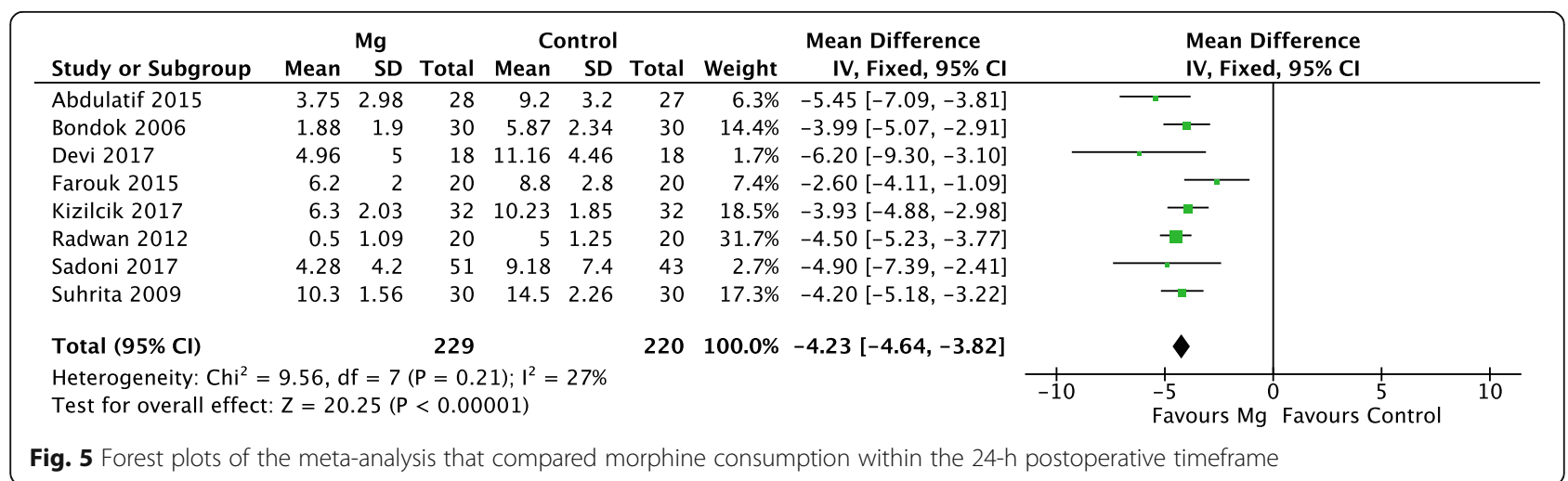




\begin{tabular}{|c|c|c|c|c|c|c|c|c|c|c|}
\hline \multirow{2}{*}{ Study or Subgroup } & \multicolumn{3}{|c|}{$\mathrm{Mg}$} & \multicolumn{3}{|c|}{ Control } & Weight & $\begin{array}{l}\text { Mean Difference } \\
\text { IV, Random, } 95 \% \mathrm{Cl}\end{array}$ & \multicolumn{2}{|c|}{$\begin{array}{l}\text { Mean Difference } \\
\text { IV, Random, } 95 \% \mathrm{CI}\end{array}$} \\
\hline & 696 & 270 & 28 & 312 & 138 & 27 & $8.7 \%$ & $384.00[271.26,496.74]$ & & \\
\hline Bondok 2006 & 667 & 198 & 30 & 49 & 13 & 30 & $9.3 \%$ & $618.00[547.00,689.00]$ & & \\
\hline Devi 2017 & 876.6 & 529.8 & 18 & 358.2 & 105.6 & 18 & $6.1 \%$ & $518.40[268.83,767.97]$ & & \\
\hline Elsharnouby (1) 2008 & 100 & 25 & 27 & 65 & 13 & 27 & $9.7 \%$ & $35.00[24.37,45.63]$ & & - \\
\hline Elsharnouby (2) 2008 & 676 & 56 & 27 & 287 & 56 & 27 & $9.6 \%$ & $389.00[359.13,418.87]$ & & - \\
\hline Farouk 2015 & 610 & 154 & 20 & 320 & 105 & 20 & $9.1 \%$ & $290.00[208.31,371.69]$ & & \\
\hline Kemalettin 2011 & 480 & 114 & 30 & 378 & 108 & 30 & $9.4 \%$ & $102.00[45.81,158.19]$ & & - \\
\hline Radwan 2012 & 528 & 37 & 20 & 317 & 22.5 & 20 & $9.7 \%$ & $211.00[192.02,229.98]$ & & $=$ \\
\hline Sadoni 2017 & 112.9 & 36.1 & 51 & 95.1 & 31.6 & 43 & $9.7 \%$ & $17.80[4.11,31.49]$ & 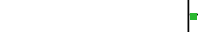 & $=$ \\
\hline Suhrita 2009 & 739.2 & 168 & 30 & 308.4 & 72 & 30 & $9.3 \%$ & $430.80[365.39,496.21]$ & & -- \\
\hline Venkateshamurthy 2018 & 1,122 & 189 & 30 & 384 & 95.4 & 30 & $9.2 \%$ & $738.00[662.24,813.76]$ & & \\
\hline & & & 311 & & & \multicolumn{5}{|c|}{$\begin{array}{l}\text { Total }(95 \% \mathrm{Cl}) \\
\text { Heterogeneity: } \mathrm{Tau}^{2}=27438.56 ; \mathrm{Chi}^{2}=1404.05, \mathrm{df}=10(\mathrm{P}<0.00001) ; I^{2}=99 \%\end{array}$} \\
\hline $\begin{array}{l}\text { Heterogeneity: } \operatorname{Tau}^{2}=27 \\
\text { Test for overall effect: } Z=\end{array}$ & $\begin{array}{l}38.56 ; C \\
6.39(P\end{array}$ & $\begin{array}{l}\mathrm{Chi}^{2}=1 \\
<0.000\end{array}$ & $\begin{array}{l}404.05 \\
001)\end{array}$ & $\mathrm{df}=1$ & $0(\mathrm{P}<$ & 0.0000 & 1) $; 1^{2}=99$ & $9 \%$ & 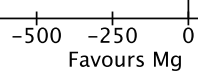 & $\begin{array}{rr}250 & 1 \\
\text { Favours Control }\end{array}$ \\
\hline
\end{tabular}

Fig. 6 Forest plots of the meta-analysis that compared the time to first analgesic request within the 24-h postoperative timeframe

articles reported adverse reactions, there was no statistically significant difference between the comparable groups. Currently, IA Mg is not considered a standard strategy for postoperative pain control. However, these results of this meta-analysis based on 11 clinical RCTs provide strong evidence that IA $\mathrm{Mg}$ is useful and safe. This method can be an effective coadjuvant treatment for postoperative pain management after arthroscopic knee surgery.

$\mathrm{Mg}$ has been used widely for many indications. As to the analgesic effect, $\mathrm{Mg}$ does not possess direct analgesic activity, as its function primarily relies on its role as physiological NMDA receptor antagonists [11]. Nociceptive sensitization of pain stimuli requires calcium for the release of neurotransmitters and other substances. The potential mechanism of the antinociceptive effects of $\mathrm{Mg}$ may be that Mg blocks the calcium channel in a voltagedependent way. $\mathrm{Mg}$ can produce a dramatic reduction of NMDA-induced currents. In the knee joint, NMDA receptors are located not only in the peripheral termini of primary afferent fibers but also in cellular elements such as immune cells and synoviocytes [39]. Therefore, it is possible that local $\mathrm{Mg}$ administration could provide analgesic effects through an IA route.

Furthermore, $\mathrm{Mg}$ also has other beneficial biological effects. Some research showed that adding Mg to a local anesthetic can reduce toxic effect of the latter to articular chondrocytes [40]. Besides, local Mg administration could recruit endogenous stem cells and promote fibrocartilaginous matrix synthesis, promoting in situ meniscal repair [41]. $\mathrm{Mg}$ deficiency in the extracellular matrix of a cartilage may lead to typical joint cartilage lesions [42]. In contrast, high concentrations of IA Mg can significantly inhibit extracellular matrix calcification and protect articular cartilage [43, 44]. Similarly, clinical trials have found that subjects with lower levels of serum $\mathrm{Mg}$ had a higher prevalence of knee chondrocalcinosis [45]. Further study is still needed to clarify the mechanism of the effect of magnesium.
The results of this study are in accordance with the findings of several published RCTs with reasonable design and adequate follow-up time [46-48]. Although $\mathrm{Mg}$ were used in different ways in clinical practice, the above evidences indicate an overall beneficial effect of $\mathrm{Mg}$ on postoperative pain relief. This strategy is suitable not only for arthroscopic knee surgery but also for multiple orthopedic surgeries. Better pain control at early postoperative stage may accelerate the rapid recovery and functional rehabilitation after joint surgery.

Concerns about Mg-related complications still remain. Three trials reported adverse reactions in this metaanalysis. Postoperative shivering is a common manifestation after anesthesia, which can lead to perioperative ischemia [49]. However, Gildasio et al. reported that perioperative systemic $\mathrm{Mg}$ can reduce the incidence rates of postoperative shivering [50]. Another concern is the increased risk of infection, as previous studies have shown that preoperative IA injections increase the risk of infection after total knee arthroplasty [51], especially corticosteroid or hyaluronic acid injection within 3 months of total knee arthroplasty [52]. However, different from IA injection prior to total knee arthroplasty, IA $\mathrm{Mg}$ injection during knee arthroscopy is much safer due to its simplicity, short operative time, and rigid aseptic technique. More importantly, IA injections of $\mathrm{Mg}$ can attenuate osteoarthritis progression and suppress synovial inflammation [53]. Moreover, no relevant joint infections have been reported in clinical trials.

\section{Strengths and limitations}

This is the first study that examined the analgesic effects of IA $\mathrm{Mg}$ after arthroscopic surgery, and the results demonstrated its efficacy and safety. The findings have important clinical implication, providing a novel strategy for the pain management. Then, the literature search is thorough and comprehensive, and the included studies are all eligible RCTs, which are considered the greatest level of evidence. Overall, the methodological quality of 
included studies is moderate or high. All these strengths may ensure the accuracy and reliability of findings.

The limitations of this study should also be acknowledged. First, this meta-analysis included 11 eligible studies (12 trials), 5 trials compared $\mathrm{Mg}$ with saline alone and the rest compared $\mathrm{Mg}$ plus analgesic with analgesic alone. The former was not sufficiently rigorous because single saline injection was not a standard clinical practice for analgesia, and it was used as only a placebo in these cases. Second, the heterogeneity was high for some outcomes, which could affect the results. After careful analysis, we found that the different types of surgery, anesthesia, IA drugs, and data recording methods may all account for the heterogeneity. Finally, the dosages of IA $\mathrm{Mg}$ were different with a large range in each group. It is difficult to determine the optimal dosage to truly evaluate the safety of IA Mg administration.

\section{Conclusions}

In conclusion, the current results suggest that IA $\mathrm{Mg}$ can significantly reduce the pain intensity and reduce additional analgesic consumption after arthroscopic knee surgery within postoperative $24 \mathrm{~h}$. This strategy appears as an effective and safe coadjuvant treatment for postoperative pain control after arthroscopic knee surgery.

\section{Abbreviations \\ IA: Intra-articularMgMagnesiumNMDAN-Methyl-D-aspartateVASVisual analog scaleNRSNumerical rating scaleIVIntravenousRCTRandomized controlled trialPRISMAPreferred Reporting Items for Systematic Reviews and Meta- AnalysesGRADEGrading of Recommendations Assessment, Development and EvaluationSDStandard deviationMDMean differencesCIConfidence interval/2Statistical heterogeneityNSample size}

\section{Acknowledgements}

Not applicable.

\begin{abstract}
Authors' contributions
All authors contributed to the study conception and design. The literature search was performed by Lijun Shi, Haiyun Zhu, and Jinhui Ma. Article selection and data extraction were performed by Lijun Shi and Lili Shi. Assessments of risk of bias and methodological quality were performed by Fuqiang Gao and Wei Sun. The first draft of the manuscript was written by Lijun Shi; and Haiyun Zhu and Jinhui Ma assisted with the preparation of the manuscript. The authors read and approved the final manuscript.
\end{abstract}

\section{Funding}

This study was funded by the Natural Science Foundation of China (grant numbers 81871830, 81672236, and 82072524), the Biomedical Translational Engineering Research Center of BUCT-CJFH (grant number RZ2020-02), and Graduate Innovation Foundation of Peking Union Medical College (grant number 2019-1002-91).

\section{Availability of data and materials}

The datasets generated/analyzed during the current study are available.

\section{Ethics approval and consent to participate}

Not applicable.

\section{Consent for publication}

Not applicable.

\section{Competing interests}

The authors declare that they have no competing interests.

\section{Author details}

${ }^{1}$ Department of Orthopedic, Surgery Graduate School of Peking Union Medical College, China-Japan Friendship institute of Clinical Medicine, 2 Yinghuadong Road, Chaoyang District, 100029 Beijing, China. ${ }^{2}$ Department of Intensive Care Unit, Tianjin Academy of Traditional Chinese Medicine Affiliated Hospital, 354 North Road, Hongqiao District, Tianjin 300120, China. ${ }^{3}$ Department of Orthopaedic Surgery, China-Japan Friendship Hospital, 2 Yinghuadong Road, Chaoyang District, Beijing 100029, China. ${ }^{4}$ Department of Gastroenterology, Henan Provincial People's Hospital, Weiwu road No 7, Jinshui district, Zhengzhou City 450003, Henan province, China.

Received: 19 November 2020 Accepted: 25 January 2021

Published online: 05 February 2021

\section{References}

1. Tiftikçi U, Serbest S. Does the location of placement of meniscal sutures have a clinical effect in the all-inside repair of meniscocapsular tears? J Orthop Surg Res. 2017;12(1):87.

2. Tiftikçi U, Serbest S. Repair of isolated horizontal meniscal tears with allinside suture materials using the overlock method: outcome study with a minimum 2-year follow-up. J Orthop Surg Res. 2016;11(1):131.

3. Rawal N. Postoperative pain management in day surgery. Anaesthesia. 1998; 53(Suppl 2):50-2.

4. Terkawi AS, Mavridis D, Sessler DI, Nunemaker MS, Doais KS, Terkawi RS, Terkawi YS, Petropoulou M, Nemergut EC. Pain management modalities after total knee arthroplasty: a network meta-analysis of 170 randomized controlled trials. Anesthesiology. 2017;126(5):923-7.

5. Manuar MB, Majumdar S, Das A, Hajra BK, Dutta S, Mukherjee D, Mitra T, Kundu R. Pain relief after arthroscopic knee surgery: a comparison of intraarticular ropivacaine, fentanyl, and dexmedetomidine: a prospective, double-blinded, randomized controlled study. Saudi J Anaesth. 2014;8(2): 233-7.

6. Zou Z, An MM, Xie Q, Chen XY, Zhang H, Liu GJ, Shi XY. Single dose intraarticular morphine for pain control after knee arthroscopy. Cochrane Database Syst Rev. 2016;2016(5):CD008918.

7. Sun QB, Liu SD, Meng QJ, Qu HZ, Zhang Z. Single administration of intraarticular bupivacaine in arthroscopic knee surgery: a systematic review and meta-analysis. BMC Musculoskelet Disord. 2015;16:21.

8. Gentili M, Houssel P, Osman M, Henel D, Juhel A, Bonnet F. Intra-articular morphine and clonidine produce comparable analgesia but the combination is not more effective. Br J Anaesth. 1997;79(5):660-1.

9. Yang LC, Chen LM, Wang CJ, Buerkle H. Postoperative analgesia by intraarticular neostigmine in patients undergoing knee arthroscopy. Anesthesiology. 1998;88(2):334-9.

10. Li C, Qu J. Efficacy of dexmedetomidine for pain management in knee arthroscopy: a systematic review and meta-analysis. Medicine (Baltimore). 2017;96: e7938.

11. Fawcett WJ, Haxby EJ, Male DA. Magnesium: physiology and pharmacology. Br J Anaesth. 1999:83(2):302-20.

12. McCarthy RJ, Kroin JS, Tuman KJ, Penn RD, Ivankovich AD. Antinociceptive potentiation and attenuation of tolerance by intrathecal co-infusion of magnesium sulfate and morphine in rats. Anesth Analg. 1998;86(4):830-6.

13. Woolf CJ. Somatic pain--pathogenesis and prevention. Br J Anaesth. 1995; 75(2):169-76

14. Iwatsu O, Ushida T, Tani T, Lawand NB, Yamamoto H. Peripheral administration of magnesium sulfate and ketamine hydrochloride produces hypesthesia to mechanical stimuli in humans. Journal of Health Science. 2002:48(1):69-72.

15. Cairns BE, Svensson P, Wang K, Hupfeld S, Graven-Nielsen T, Sessle BJ, Berde $\mathrm{CB}$, Arendt-Nielsen L. Activation of peripheral NMDA receptors contributes to human pain and rat afferent discharges evoked by injection of glutamate into the masseter muscle. J Neurophysiol. 2003;90(4):2098-105.

16. Yu XM, Sessle BJ, Haas DA, Izzo A, Vernon H, Hu JW. Involvement of NMDA receptor mechanisms in jaw electromyographic activity and plasma extravasation induced by inflammatory irritant application to temporomandibular joint region of rats. Pain. 1996;68(1):169-78.

17. Bilir A, Gulec S, Erkan A, Ozcelik A. Epidural magnesium reduces postoperative analgesic requirement. Br J Anaesth. 2007;98(4):519-23. 
18. Faiz SH, Rahimzadeh P, Sakhaei M, Imani F, Derakhshan P. Anesthetic effects of adding intrathecal neostigmine or magnesium sulphate to bupivacaine in patients under lower extremities surgeries. J Res Med Sci. 2012;17(10):918-22.

19. Hwang JY, Na HS, Jeon YT, Ro YJ, Kim CS, Do SH. I.V. infusion of magnesium sulphate during spinal anaesthesia improves postoperative analgesia. $\mathrm{Br} J$ Anaesth. 2010;104(1):89-93.

20. Na HS, Lee JH, Hwang JY, Ryu JH, Han SH, Jeon YT, Do SH. Effects of magnesium sulphate on intraoperative neuromuscular blocking agent requirements and postoperative analgesia in children with cerebral palsy. $\mathrm{Br}$ J Anaesth. 2010;104(3):344-50.

21. Ko SH, Lim HR, Kim DC, Han YJ, Choe H, Song HS. Magnesium sulfate does not reduce postoperative analgesic requirements. Anesthesiology. 2001; 95(3):640-6.

22. Wu CL, Raja SN. Treatment of acute postoperative pain. Lancet. 2011; 377(9784):2215-25.

23. Liberati A, Altman DG, Tetzlaff J, Mulrow C, Gotzsche PC, loannidis JP, Clarke M, Devereaux PJ, Kleijnen J, Moher D. The PRISMA statement for reporting systematic reviews and meta-analyses of studies that evaluate health care interventions: explanation and elaboration. J Clin Epidemiol. 2009;62(10):e1-34.

24. Hozo SP, Djulbegovic B, Hozo I. Estimating the mean and variance from the median, range, and the size of a sample. BMC Med Res Methodol. 2005;5:13.

25. Macintyre PE, Ready LB. Pharmacology of opioids, acute pain management-a practical guide, 2nd edition. Edited by Macintyre PE, Ready LB, Philadephia. Harcourt Health Sciences. 2001;15-49.

26. Higgins JPT, Green S. Cochrane handbook for systematic reviews of interventions version 5.1.0. The Cochrane collaboration. http://www. cochrane-handbook.org 2011

27. Guyatt GH, Oxman AD, Vist GE, Kunz R, Falck-Ytter Y, Alonso-Coello P, Schünemann HJ. GRADE Working Group. GRADE: an emerging consensus on rating quality of evidence and strength of recommendations. BMJ. 2008; 336(7650):924-6.

28. Sadoni H, Toloueghamari B, Teymourei K, Moosavi SS, Inloo FM, Ghomeishi A, Dastoorpoor M. Effects of intra-articular magnesium sulfate injection in post-operative pain in knee arthroscopy: a prospective comparative study. Asian J Pharm. 2017;11(2):1-4.

29. Devi MM, Gupta S, Amaravathi R, Udupa S, Hegde A, Ghosh S. Comparison of efficacy of intra-articular plain bupivacaine and bupivacaine with adjuvants (dexmedetomidine and magnesium sulfate) for postoperative analgesia in arthroscopic knee surgeries: a prospective, randomized controlled trial. Anesth Essays Res. 2018;12(4):848-54.

30. Abdulatif M, Amin SMM, Aboul-Ela A, Samuel EWM, Abdel-Hakim SMA. Intra-articular versus intravenous magnesium-sulfate as adjuvant to femoral nerve block in arthroscopic knee surgery under general anesthesia: randomized controlled trial. Egypt J Anaesth. 2015;31:239-46.

31. Farouk S, Aly A. A comparison of intra-articular magnesium and/or morphine with bupivacaine for postoperative analgesia after arthroscopic knee surgery. J Anesth. 2009;23:508-12.

32. Radwan YA, Alfeky AA, Faramawi MF. Analgesic effect of intra-articular magnesium sulphate compared with bupivacaine after knee arthroscopic menisectomy. J Adv Res 2013:4:(4) 355-60

33. Koltka K, Koknel-Talu G, Asik M, Ozyalcin S. Comparison of efficacy of intraarticular application of magnesium, levobupivacaine and lornoxicam with placebo in arthroscopic surgery. Knee Surg Sports Traumatol Arthrosc. 2011;19(11):1884-9.

34. Suhrita P, Prasad DB, Sandip G, Satrajit D, Niloy C. Postoperative analgesia for arthroscopic knee surgery: a comparison between intra-articular bupivacaine alone or in combination with magnesium sulphate or clonidine. Pharmacologyonline. 2009;3:938-43.

35. Kizilcik N, Özler T, Menda F, Uluçay Ç, Köner Ö, Altintaş F. The effects of intra-articular levobupivacain versus levobupivacain plus magnesium sulfate on postoperative analgesia in patients undergoing arthroscopic meniscectomy: a prospective randomized controlled study. Acta Orthop Traumatol Turc. 2017;51(2):104-9.

36. Bondok RS, El-Hady AMA. Intra-articular magnesium is effective for postoperative analgesia in arthroscopic knee surgery. Br J Anaesth. 2006; 97(3):389-92.

37. Elsharnouby NM, Eid HE, Abou Elezz NF, Moharram AN. Intraarticular injection of magnesium sulphate and/or bupivacaine for postoperative analgesia after arthroscopic knee surgery. Anesth Analg. 2008;106(5):1548-52.

38. Venkateshamurthy CB, Gangappa RC, Nagarajarao GK. Evaluation of the efficacy of intra-articular inj. magnesium sulphate in combination with inj. bupivacaine for post-operative pain relief following diagnostic arthroscopy of the knee joint- a comparative prospective study. J Evol Med Dent Sci. 2018;7(39):4262-7.

39. Lawand NB, Willis WD, Westlund KN. Excitatory amino acid receptor involvement in peripheral nociceptive transmission in rats. Eur J Pharmacol. 1997;324(2-3):169-77.

40. Baker JF, Byrne DP, Walsh PM, Mulhall KJ. Human chondrocyte viability after treatment with local anesthetic and/or magnesium: results from an in vitro study. Arthroscopy. 2011;27(2):213-7.

41. Zhang ZZ, Zhou YF, Li WP, Jiang C, Chen Z, Luo H, Song B. Local administration of magnesium promotes meniscal healing through homing of endogenous stem cells: a proof-of-concept study. Am J Sports Med. 2019:47(4):954-67.

42. Stahlmann R, Forster C, Shakibaei M, Vormann J, Gunther T, Merker HJ. Magnesium deficiency induces joint cartilage lesions in juvenile rats which are identical to quinolone-induced arthropathy. Antimicrob Agents Chemother. 1995;39(9):2013-8.

43. Yue J, Jin S, Gu S, Sun R, Liang Q. High concentration magnesium inhibits extracellular matrix calcification and protects articular cartilage via Erk/ autophagy pathway. J Cell Physiol. 2019;234(12):23190-201.

44. Feyerabend F, Witte F, Kammal M, Willumeit R. Unphysiologically high magnesium concentrations support chondrocyte proliferation and redifferentiation. Tissue Eng. 2006;12(12):3545-56.

45. Zeng C, Wei J, Terkeltaub R, Yang T, Choi HK, Wang YL, Xie DX, Hunter DJ, Zhang Y, Li H, Cui Y, Li LJ, Lei GH. Dose-response relationship between lower serum magnesium level and higher prevalence of knee chondrocalcinosis. Arthritis Res Ther. 2017;19(1):236.

46. Shin HJ, Kim EY, Na HS, Kim TK, Kim MH, Do SH. Magnesium sulphate attenuates acute postoperative pain and increased pain intensity after surgical injury in staged bilateral total knee arthroplasty: a randomized, double-blinded, placebo-controlled trial. Br J Anaesth. 2016 Oct;117(4):497-503.

47. Samir EM, Badawy SS, Hassan AR. Intrathecal vs intravenous magnesium as an adjuvant to bupivacaine spinal anesthesia for total hip arthroplasty[J]. Egyptian Journal of Anaesthesia. 2013;29(4):395-400

48. Xu X, Wen H, Hu Y, Liu Z, Pan X. Efficacy of intra-articular magnesium for postoperative analgesia in total hip arthroplasty. Biomed Rep. 2017 Feb;6(2):232-6.

49. Nakasuji M, Nakamura M, Imanaka N, Tanaka M, Nomura M, Suh SH. Intraoperative high-dose remifentanil increases post-anaesthetic shivering. Br J Anaesth. 2010;105(2):162-7.

50. De Oliveira GS Jr, Castro-Alves $\sqcup$, Khan JH, McCarthy RJ. Perioperative systemic magnesium to minimize postoperative pain: a meta-analysis of randomized controlled trials. Anesthesiology. 2013;119(1):178-90.

51. Bedard NA, Pugely AJ, Elkins JM, Duchman KR, Westermann RW, Liu SS, Gao Y, Callaghan JJ, The John N. Insall Award: do intraarticular injections increase the risk of infection after TKA? Clin Orthop Relat Res. 2017;475(1):45-52.

52. Richardson SS, Schairer WW, Sculco TP, Sculco PK. Comparison of infection risk with corticosteroid or hyaluronic acid injection prior to total knee arthroplasty. J Bone Joint Surg Am. 2019;101(2):112-8.

53. Yao H, Xu JK, Zheng NY, Wang JL, Mok SW, Lee YW, Shi L, Wang JY, Yue J, Yung SH, Hu PJ, Ruan YC, Zhang YF, Ho KW, Qin L. Intra-articular injection of magnesium chloride attenuates osteoarthritis progression in rats. Osteoarthritis Cartilage. 2019;27(12):1811-21.

\section{Publisher's Note}

Springer Nature remains neutral with regard to jurisdictional claims in published maps and institutional affiliations.

Ready to submit your research? Choose BMC and benefit from:

- fast, convenient online submission

- thorough peer review by experienced researchers in your field

- rapid publication on acceptance

- support for research data, including large and complex data types

- gold Open Access which fosters wider collaboration and increased citations

- maximum visibility for your research: over $100 \mathrm{M}$ website views per year

At $\mathrm{BMC}$, research is always in progress.

Learn more biomedcentral.com/submissions 